Pesq. Vet. Bras. 29(11):925-930, novembro 2009

\title{
Síndrome do abscesso pituitário em bezerros na Região Centro-Oeste ${ }^{1}$
}

\author{
Antônio Carlos L. Câmara ${ }^{2 *}$, José Renato J. Borges ${ }^{3}$, Roberta F. de Godoy ${ }^{3}$, \\ Augusto R.C. Moscardini ${ }^{3}$, Vanessa da Silva Mustafa ${ }^{4}$, Márcio B. de Castro ${ }^{4}$, \\ Fábio H.B. Ximenes ${ }^{3}$, Giane R. Paludo ${ }^{4}$, Simone Perecmanis ${ }^{5}$ e Vinícius O. \\ Drummond ${ }^{5}$
}

\begin{abstract}
Câmara A.C.L., Borges J.R.J., Godoy R.F., Moscardini A.R.C., Mustafa V.S., Castro M.B., Ximenes F.H.B., Paludo G.R., Perecmanis S. \& Drummond V.O. 2009. [Pituitary abscess syndrome in calves from Mid-Western Brazil.] Síndrome do abscesso pituitário em bezerros na região Centro-Oeste. Pesquisa Veterinária Brasileira 29(11):925-930. Hospital Escola de Grandes Animais da Granja do Torto, Faculdade de Agronomia e Medicina Veterinária, Universidade de Brasília, Galpão 4, Granja do Torto, Brasília, DF 70636-200. E-mail: aclcamara@yahoo.com.br

Pituitary abscess syndrome is a neurologic disease responsible for sporadic cases and outbreaks especially in calves leading to high mortality rates. This paper aimed to report the occurrence and the clinical, laboratorial and pathologic findings in three 8 to 11-month-old calves with pituitary abscess syndrome from Mid-Western Brazil. The most important clinical findings were nervous signs of cerebral and brainstem origin with clinical evolution of 7-20 days. Hematology revealed leucocytosis by neutrophilia and hyperfibrinogenemia. Cerebrospinal fluid analysis showed neutrophilic pleocytosis. Arcanobacterium pyogenes was isolated from cerebrospinal fluid. One calf recovered after antibiotic treatment. Mortality rate was $66.6 \%$ (2/3). Necropsy findings included single para-hypophyseal abscesses or located in the glandular parenchyma; one calf showed necrotizing rhinitis and another abscedative pneumonia. Histological exams of the central nervous system reveal complete absence of normal pituitary tissue due to the wide necrosis and neutrophilic inflammatory infiltrate. The authors reiterate the importance of adequate management practices to reduce incidence of several diseases especially in calves, including the pituitary abscess syndrome.
\end{abstract}

INDEX TERMS: Abscess, bacterial diseases, calves, central nervous system, pituitary.

RESUMO.- A síndrome do abscesso pituitário é uma doença neurológica responsável por casos esporádicos e surtos, principalmente em bezerros, ocasionando alto índice de mortalidade. Descreve-se a ocorrência e os acha-

\footnotetext{
${ }^{1}$ Recebido para publicação em 15 de abril de 2009.

Aceito para publicação em 22 de julho de 2009

2 Programa de Pós-Graduação em Saúde Animal, Faculdade de Agronomia e Medicina Veterinária (FAV), Universidade de Brasília (UnB). Galpão 4, Granja do Torto, Brasília, DF 70636-200, Brasil. *Autor para correspondência: aclcamara@yahoo.com.br

${ }^{3}$ Hospital Escola de Grandes Animais da Granja do Torto, FAV-UnB, Galpão 4, Granja do Torto, Brasília, DF 70636-200, Brasil.

${ }^{4}$ Laboratório de Patologia Veterinária, FAV-UnB, Av. L4 Norte, Brasília, DF 70910-900, Brasil.

${ }^{5}$ Laboratório de Microbiologia Médico Veterinária, FAV-UnB, Brasília, DF.
}

dos clínicos, laboratoriais e anátomo-patológicos em três bezerros com síndrome do abscesso pituitário no CentroOeste do Brasil. Os animais tinham 8-11 meses de idade e os sinais clínicos mais marcantes relacionaram-se aos sinais nervosos de origem cerebral e do tronco encefálico com evolução clínica de 7-20 dias. A hematologia revelou leucocitose por neutrofilia e hiperfibrinogenemia. A análise do líquido céfalo-raquidiano apresentou pleocitose neutrofílica. Arcanobacterium pyogenes foi isolado do líquido céfalo-raquidiano. Um dos bezerros apresentou recuperação após antibioticoterapia. A mortalidade foi de $66,6 \%(2 / 3)$. Os achados de necropsia consistiram em um único abscesso de localização parapituitária ou situado no parênquima da glândula; um dos bezerros apresentou rinite necrosante e outro, broncopneumonia 
abscedativa. O exame histológico do sistema nervoso central revelou ausência quase completa do tecido hipofisário normal, devido à necrose extensa e infiltrado inflamatório neutrofílico difuso concomitante. Reitera-se a importância da realização de práticas de manejo adequadas a fim de reduzir a incidência de inúmeras enfermidades, principalmente em bezerros, dentre elas a síndrome do abscesso pituitário.

TERMOS DE INDEXAÇÃO: Abscesso, bezerros, doenças bacterianas, hipófise, sistema nervoso central.

\section{INTRODUÇÃO}

A síndrome do abscesso pituitário (SAP) ou empiema basilar é uma doença neurológica caracterizada pela formação de abscessos no complexo vascular sobre o osso baso-esfenóide, podendo comprometer por extensão a glândula pituitária ou estruturas vizinhas (Radostits et al. 2007), sendo descrita em bovinos (Paredes et al. 1996, Fernandes et al. 2000, Loretti et al. 2003, Guaraná et al. 2008), caprinos (Bath et al. 2005), ovinos (Radostits et al. 2007), equinos (Reilly et al. 1994) e humanos (Su et al. 2006).

Em geral, existem quatro vias para chegada de um agente infeccioso ao sistema nervoso central: a partir da disseminação hematógena ou linfática que tem origem em diferentes locais do corpo (Morin 2004, Stöber 2005), por lesões penetrantes diretas, por extensão de uma lesão supurativa adjacente, e por infecção centrípeta via nervo periférico (Barros et al. 2006, Radostits et al. 2007).

A SAP tem sido descrita na forma de surtos ou de casos esporádicos em bezerros de três a 12 meses de idade, em consequência da rinite traumática produzida pelo uso de tabuleta nasal para desmame interrompido (Fernandes et al. 2000, Loretti et al. 2003), e, também, após a colocação de argolas nasais em bovinos de qualquer idade (Morin 2004). Arcanobacterium (Actinomyces) pyogenes é o organismo mais frequentemente isolado dessas lesões abscedativas (Fernandes et al. 2000, Loretti et al. 2003), mas uma ampla variedade de outras bactérias aeróbicas e anaeróbicas tem sido, também, isoladas em cultivo (Morin
2004). No Brasil, existem relatos de SAP em bovinos no Rio Grande do Sul (Fernandes et al. 2000, Loretti et al. 2003) e Pernambuco (Guaraná et al. 2008).

Os objetivos do presente trabalho foram relatar a ocorrência e descrever os achados clínicos, laboratoriais e anátomo-patológicos de três casos de SAP observados na Região Centro-Oeste.

\section{MATERIAL E MÉTODOS}

As fichas de acompanhamento clínico de três bezerros com síndrome do abscesso pituitário (SAP) diagnosticados no Hospital Escola de Grandes Animais da Granja do Torto, Universidade de Brasília (HVET-UnB), foram analisadas resgatando-se as informações relacionadas aos dados epidemiológicos, obtidos junto aos proprietários, além dos achados clínicos, laboratoriais e anátomo-patológicos.

Os animais foram examinados clinicamente seguindo as recomendações de Dirksen et al. (1993), enquanto o exame neurológico foi realizado de acordo com Mayhew (1989). Foram coletadas amostras sanguíneas em tubo à vácuo com anticoagulante EDTA (10\%), para realização do hemograma, determinação da proteína plasmática total e do fibrinogênio plasmático, conforme preconiza Jain (1993). Amostras do líquido céfalo-raquidiano (LCR), coletadas na cisterna cerebelo-medular (cisterna magna), foram analisadas de acordo com a metodologia proposta por Scott (1995). Uma das amostras do LCR (Caso 1) foi semeada em ágar sangue a $10 \%$ e incubada a $37^{\circ} \mathrm{C}$ por 24 horas para isolamento e identificação bioquímica de bactérias. Os animais que morreram durante o internamento hospitalar foram necropsiados. O sistema nervoso central, hipófise, rete mirabile carotídea, baço, fígado, pulmões, rim, coração e fragmentos da mucosa nasal, foram fixados em formalina a 10\%, e posteriormente, processados rotineiramente para histologia e corados pela técnica de hematoxilina-eosina (HE).

\section{RESULTADOS}

Os bezerros eram provenientes de duas propriedades rurais localizadas na Região Administrativa do Gama, Distrito Federal, e de uma propriedade no município de Água Fria, Goiás. Todos os proprietários mencionaram a ocorrência de sinais nervosos nos bezerros, enquanto dois

\section{Quadro 1. Dados epidemiológicos, evolução clínica, sinais clínicos e resolução clínica de três bezerros com síndrome} do abscesso pituitário no Centro-Oeste

\begin{tabular}{|c|c|c|c|c|c|c|c|c|c|}
\hline Caso & Raça & Sexo & $\begin{array}{l}\text { Idade } \\
\text { (meses) } \\
\text { (dias) }\end{array}$ & $\begin{array}{l}\text { Evolução } \\
\text { clínica }^{a} \\
\text { nasal }\end{array}$ & $\begin{array}{l}\text { Uso de } \\
\text { tabuleta }\end{array}$ & $\begin{array}{l}\text { Mês/ano da } \\
\text { ocorrência }\end{array}$ & Sinais clínicos & Resolução & $\begin{array}{l}\text { o Município / } \\
\text { Estado }\end{array}$ \\
\hline 1 & Holandesa & Fêmea & 11 & 10 & Não & Agosto 2002 & $\begin{array}{l}\text { Depressão, desidratação, leve hipotonia de } \\
\text { língua, nistagmo, miose bilateral, convulsões, } \\
\text { movimentos de pedalagem, opistótono, sialor- } \\
\text { réia e crepitações pulmonares }\end{array}$ & Óbito & $\begin{array}{c}\text { Região } \\
\text { Administrativa } \\
\text { do Gama/DF }\end{array}$ \\
\hline 3 & Tabapuã & Macho & 10 & 20 & Sim & Janeiro 2005 & $\begin{array}{l}\text { Depressão, febre, sialorréia, secreção nasal } \\
\text { sero-purulenta e pressão da cabeça contra } \\
\text { obstáculos }\end{array}$ & Óbito & Água Fria/GO \\
\hline
\end{tabular}

\footnotetext{
a Tempo decorrido do início da sintomatologia clínica observados pelos proprietário até o atendimento no HVET-UNB.
} 
relataram, também, o uso de tabuleta para desmame interrompido sem histórico prévio de doença associada ao uso deste dispositivo.

Os dados epidemiológicos, evolução clínica, principais sinais clínicos e desfecho são apresentados no Quadro 1. Os sinais de origem cerebral (depressão, convulsões, andar em círculos e pressão da cabeça contra obstáculos) e do tronco encefálico (cegueira, miose, paralisia mandibular parcial, nistagmo e hipotonia de língua) foram os mais observados. A evolução clínica foi de 7-20 dias. Outros sinais clínicos foram febre, desidratação, sialorréia, além de crepitações pulmonares em um dos bezerros (Caso 1). O exame das fossas nasais revelou a presença de úlceras simétricas e bilaterais de aproximadamente $2 \mathrm{~cm}$ de diâmetro no tabique nasal dos animais que usavam tabuleta para desmame interrompido (Fig.1); além de secreção sero-purulenta no Caso 3.

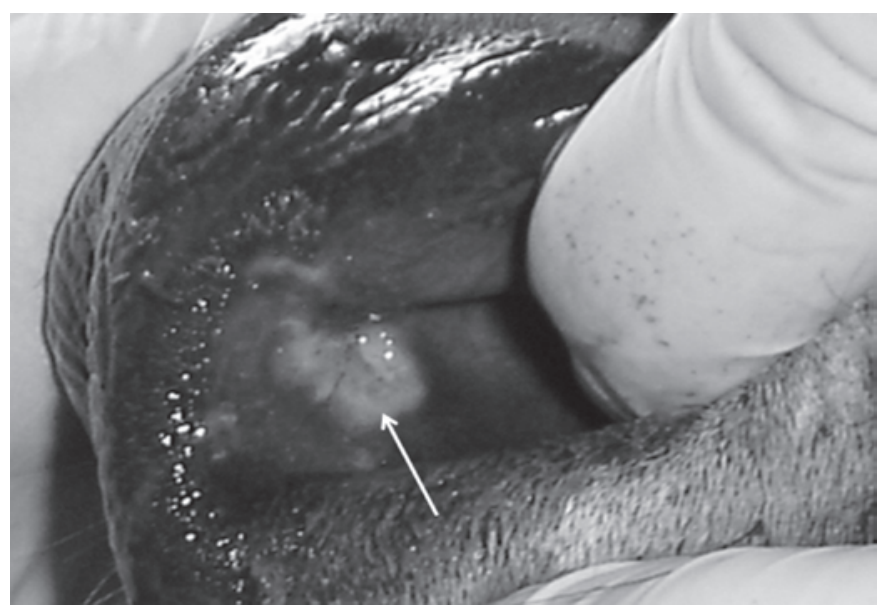

Fig.1. Narina esquerda apresentando lesão única com secreção purulenta (seta) decorrente do uso de tabuleta nasal para desmame interrompido (Caso 2). A lesão era bilateral.

Os valores hematológicos, da proteína plasmática total e do fibrinogênio plasmático são apresentados no Quadro 2. Nos Casos 1 e 2, o hemograma revelou marcante leucocitose por neutrofilia, com inversão da relação neutrófilos: linfócitos, sendo ainda constatado desvio à esquerda regenerativo em um dos animais (Caso 2). No Caso 3 foi evidenciado o quadro de linfopenia absoluta e desvio à esquerda degenerativo, onde o número de neutrófilos imaturos (bastonetes) ultrapassou a quantidade de neutrófilos segmentados. Todos os bezerros apresentaram hiperfibrinogenemia. Os demais parâmetros encontravam-se dentro dos limites fisiológicos para a espécie (Kramer 2000).

Os resultados das análises do LCR são apresentados no Quadro 3. Observaram-se coloração avermelhada, aspecto turvo e aumento do valor de proteína em um bezerro (Caso 1), enquanto tais parâmetros estavam dentro dos limites fisiológicos para bovinos (Scott 1995) nos demais bezerros. A quantidade de células nucleadas era de 50,0; 17,7 e 15,5/ $\mu \mathrm{L}$ nos Casos 1, 2 e 3, respectivamente.
Quadro 2. Valores hematológicos, da proteína plasmática total e do fibrinogênio plasmático em três casos de síndrome do abscesso pituitário em bezerros no Centro-Oeste

\begin{tabular}{ccccc}
\hline Parâmetros & Caso 1 & Caso 2 & Caso 3 & $\begin{array}{c}\text { Valores } \\
\text { de referência }\end{array}$ \\
\hline Hematócrito $(\%)$ & 33 & 38 & 33 & $24-46$ \\
Hemácias $\left(\times 10^{6} / \mu \mathrm{L}\right)$ & 8,2 & 9,1 & 8,1 & $5-10$ \\
Hemoglobina $(\mathrm{g} / \mathrm{dL})$ & 11,3 & 11,6 & 10,4 & $8-15$ \\
$\mathrm{VCM}^{\mathrm{a}}(\mathrm{fL})$ & 40,2 & 41,7 & 40,7 & $40-60$ \\
$\mathrm{CHCM}^{\mathrm{b}}(\%)$ & 34,3 & 30,5 & 31,5 & $30-36$ \\
$\mathrm{PPT}^{\mathrm{C}}(\mathrm{g} / \mathrm{dL})$ & 9,4 & 8,6 & 7,8 & $7,0-8,5$ \\
$\mathrm{FPd}^{\mathrm{d}}(\mathrm{mg} / \mathrm{dL})$ & 900 & 800 & 1000 & $300-700$ \\
Leucócitos Totais $(/ \mu \mathrm{L})$ & 23700 & 27100 & 7300 & $4-12$ \\
Neutrófilos $(/ \mu \mathrm{L})$ & 15705 & 15989 & 3212 & $600-4000$ \\
Linfócitos $(/ \mu \mathrm{L})$ & 6873 & 2410 & 1825 & $2500-7500$ \\
Monócitos $(/ \mu \mathrm{L})$ & 1185 & 3794 & 438 & $25-840$ \\
Eosinófilos $(/ \mu \mathrm{L})$ & 237 & - & - & $0-2400$ \\
Bastonetes $(/ \mu \mathrm{L})$ & - & 1825 & 4065 & -
\end{tabular}

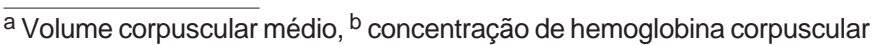
média,

${ }^{\mathrm{c}}$ proteína plasmática total, ${ }^{\mathrm{d}}$ fibrinogênio plasmático, ${ }^{\mathrm{e}}$ segundo Kramer (2000).

Quadro 3. Resultados do exame físico $(n=3)$, contagem diferencial de células $(n=2)$ e cultura microbiológica $(n=1)$ no LCR de bezerros com síndrome do abscesso pituitário no Centro-Oeste

\begin{tabular}{ccccc}
\hline Parâmetros & Caso 1 & Caso 2 & Caso 3 & $\begin{array}{c}\text { Valores } \\
\text { de referênciae }\end{array}$ \\
\hline Volume $(\mathrm{mL})$ & 2 & 4 & 0,8 & $\begin{array}{c}\text { Variável } \\
\text { Aspecto }\end{array}$ \\
Cor & \multicolumn{2}{c}{$\begin{array}{c}\text { Turvo } \\
\text { Avermelhadolncolor }\end{array}$} & $\begin{array}{c}\text { Límpido } \\
\text { Límpido }\end{array}$ & $\begin{array}{c}\text { Límpolor } \\
\text { Incolor }\end{array}$ \\
Densidade & 1,014 & 1,006 & 1,008 & $<1,010$ \\
Proteína $(\mathrm{g} / \mathrm{dL})$ & 0,5 & 0,363 & 0,412 & $<0,4$ \\
Hemácias $(/ \mu \mathrm{L})$ & 72000 & 0 & 11 & Poucas a \\
& & & & nenhuma \\
Células nucleadas $(/ \mu \mathrm{L})$ & 50 & 15,5 & 17,7 & $0-10$ \\
Neutrófilos $(\%)$ & $\mathrm{ND}$ & 14 & 7 & - \\
Linfócitos $(\%)$ & $\mathrm{ND}$ & 39 & 13 & $60-80$ \\
Monócitos $(\%)$ & $\mathrm{ND}$ & 43 & 68 & $20-40$ \\
Eosinófilos $(\%)$ & $\mathrm{ND}$ & 1 & 1 & - \\
Bastonetes $(\%)$ & $\mathrm{ND}$ & 3 & 11 & - \\
Cultura microbiológica Positiva para & $\mathrm{ND}$ & $\mathrm{ND}$ & -
\end{tabular}
A. pyogenes

$\bar{a}$ Não determinado, b segundo Scott (1995).

Em dois casos foi realizada a contagem diferencial, sendo evidenciado pleocitose neutrofílica com presença de bastonetes. $\mathrm{O}$ microrganismo $A$. pyogenes foi isolado na alíquota do LCR (Caso 1) submetida à cultura bacteriana.

Dois animais morreram durante o internamento hospitalar e foram necropsiados, enquanto um dos bezerros (Caso 2) se recuperou após tratamento com associação de penicilinas e estreptomicina, porém observou-se sequela neurológica de incoordenação motora discreta. Os principais achados de necropsia consistiam em abscesso único no assoalho da cavidade craniana, de localização parapituitária ou situado no parênquima da pituitária comprimindo dorsalmente o tronco encefálico (Fig.2). Em um dos bezerros (Caso 3) observou-se rinite necrosante, com úlceras de aproximadamente $2 \mathrm{~cm}$ de diâmetro na porção 

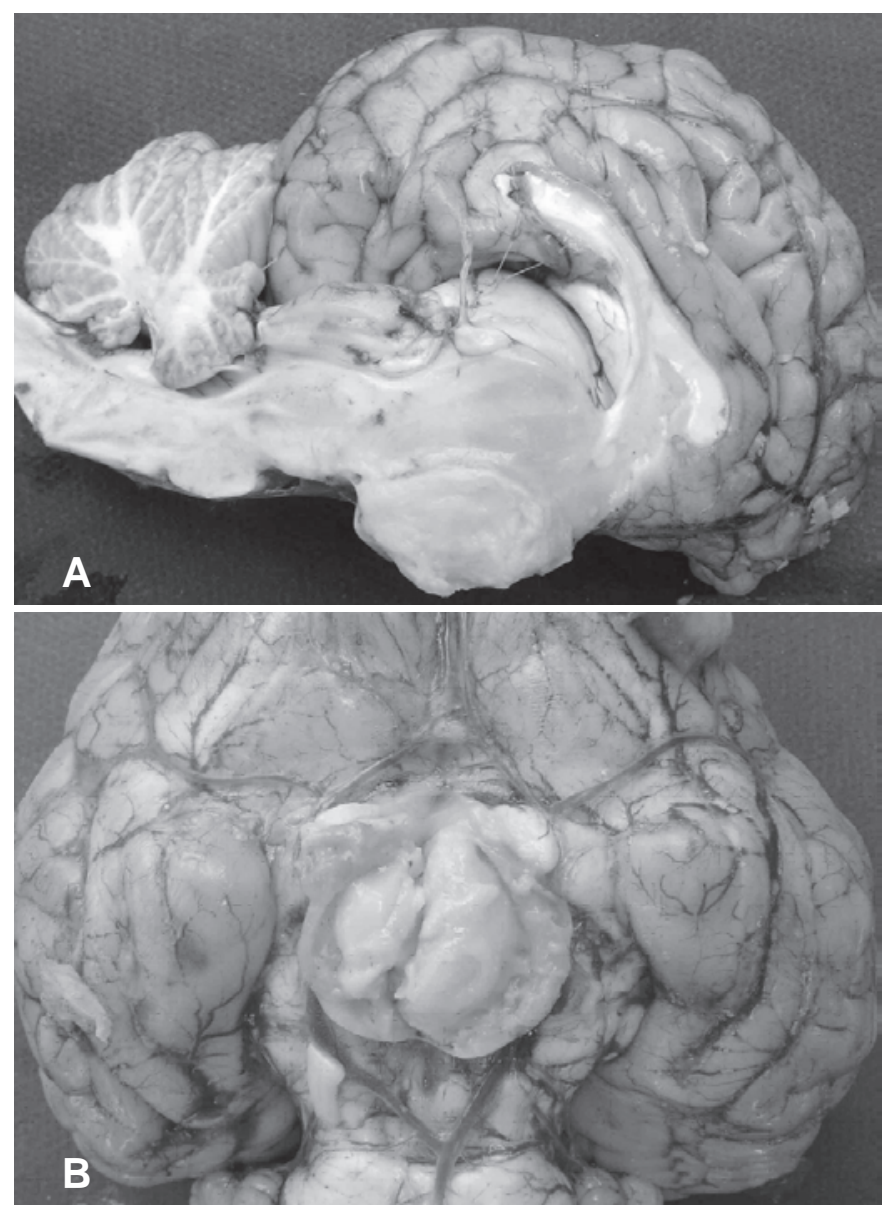

Fig.2. (A) Corte sagital do sistema nervoso central mostrando a compressão do tronco encefálico pelo abscesso pituitário (Caso 1). (B) Abscesso de localização para-pituitária com material purulento (Caso 3).

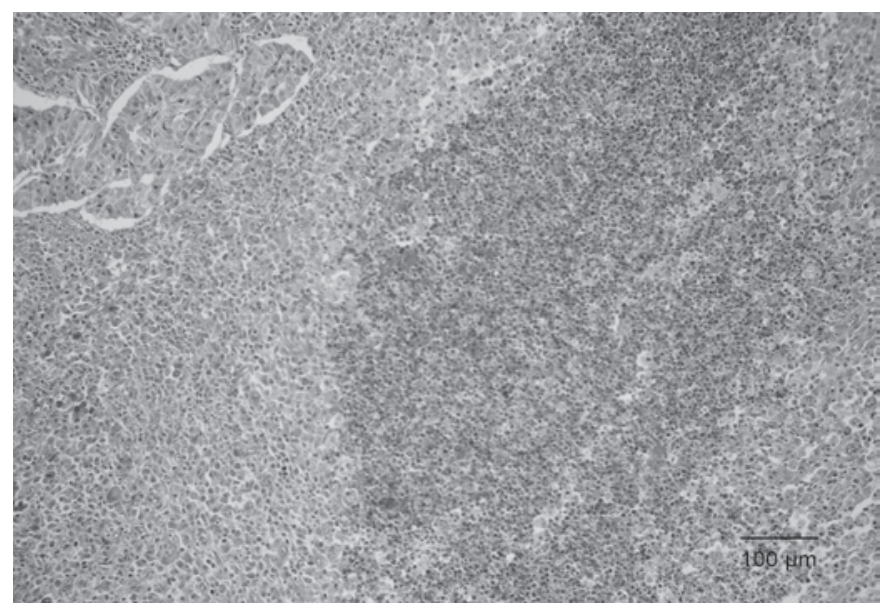

Fig.3. Infiltrado inflamatório neutrofílico acentuado focalmente extenso na hipófise. HE, obj.100x.

anterior da cavidade nasal, simétricas e bilaterais, recobertas por exsudato fibrinonecrótico. No Caso 1, os pulmões estavam congestos e no parênquima evidenciavamse múltiplas nodulações com tamanho de até $4 \mathrm{~cm}$ de diâmetro, que ao corte deixavam fluir conteúdo purulento.

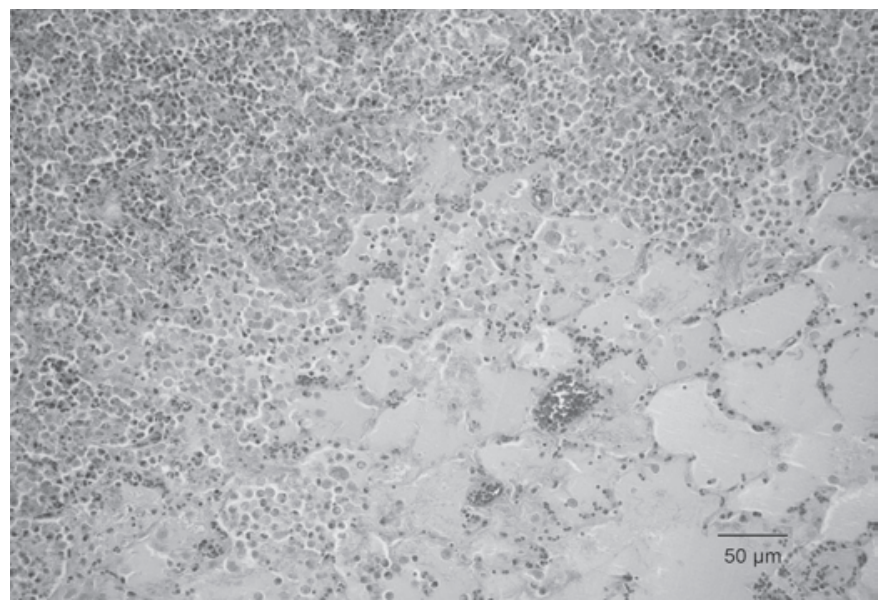

Fig.4. Edema alveolar multifocal e acentuado infiltrado inflamatório composto por neutrófilos e histiócitos (Caso 1). HE, obj.40x.

Os achados microscópicos revelaram na região da hipófise, área de necrose extensa com debris celulares, quantidade acentuada de colônias bacterianas intralesionais e infiltrado inflamatório neutrofílico em meio à extensa necrose, com ausência quase completa de tecido hipofisário normal (Fig.3). Circundando a área de necrose, evidenciou-se infiltrado inflamatório focal constituído por histiócitos e plasmócitos, além de proliferação acentuada de tecido conjuntivo fibroso. Em meio a essa fibrose observou-se infiltrado inflamatório linfohistiocítico multifocal moderado. Alguns focos inflamatórios discretos, compostos por linfócitos e histiócitos, e necrose multifocal moderada foram observados no gânglio trigeminal. Outros achados incluíam manguitos perivasculares multifocais constituídos por linfócitos e histiócitos, com intensidade variando de moderada a acentuada, no córtex cerebral, cerebelo, região do hipocampo e tronco encefálico. No Caso 1, os abscessos no parênquima pulmonar eram histologicamente semelhantes aos observados na região pituitária (Fig.4).

\section{DISCUSSÃO}

A SAP é uma doença neurológica que se apresenta de forma esporádica ou em surtos, afetando principalmente bezerros (Fernandes et al. 2000, Loretti et al. 2003, Radostits et al. 2007), sendo observados graus variados de envolvimento de nervos cranianos (Fernandes \& Schild 2007). No presente estudo ocorreram três casos esporádicos em propriedades sem histórico de doença, sendo os sinais nervosos descritos relacionados à pressão exercida pelo abscesso nas estruturas circunvizinhas, evidenciando-se paralisia ou hemiplegia uni ou bilateral dos nervos cranianos, principalmente o abducente, o trigêmeo e o oculomotor, observadas, também, em outros relatos da enfermidade (Fernandes et al. 2000, Loretti et al. 2003, Morin 2004). Entretanto, os sinais clínicos são variados e estão relacionados com a localização dos abscessos, que podem inicialmente envolver o complexo vascular e/ou 
pituitária e, posteriormente, atingir as meninges do cérebro, cerebelo e parênquima cerebral (Loretti et al. 2003).

As alterações no leucograma e a hiperfibrinogenemia são sugestivos de um processo inflamatório agudo, e comumente decorrente de infecções bacterianas (Jones \& Allison 2007). As alterações na coloração, densidade e valor da proteína no LCR de um dos bezerros (Quadro 3) decorrem da contaminação sanguínea por trauma acidental dos vasos das leptomeninges. Este achado é confirmado pela ausência de hemácias fagocitadas e xantocromia (Scott 2004), impossibilitando a contagem diferencial de células. A diferenciação das células nucleadas encontradas no LCR de ruminantes é composta quase que exclusivamente por células mononucleares (Scott, 1995). As alterações descritas no número de células nucleadas e contagem diferencial de células são usualmente sinais de infecção bacteriana, sendo evidenciada a elevação de granulócitos neutrofílicos polimorfonucleados em processos purulentos, como abscessos cerebrais ou medulares e meningoencefalomielites sépticas (Stöber 1993, Scott 2004). Resultados semelhantes são citados em bovinos com abscessos no sistema nervoso central (Stockol et al. 2009). A cultura bacteriana identifi$\operatorname{cou} A$. pyogenes, bactéria mais comumente isolada em lesões supurativas crônicas do cérebro (Fernandes et al. 2000, Loretti et al. 2003). Outras bactérias, como Staphylococcus sp., Streptococcus sp., Fusobacterium necrophorum e Corynebacterium pseudotuberculosis podem, também, ser encontradas (Morin 2004, Radostits et al. 2007).

Os achados anátomo-patológicos são semelhantes aos descritos em relatos anteriores da doença (Paredes et al. 1998, Fernandes et al. 2000, Loretti et al. 2003, Guaraná et al. 2008). $O$ achado de rinite necrosante (Casos 2 e 3 ) sugere fortemente que tais casos de SAP são secundários à rinite traumática, como em relatos prévios no Rio Grande do Sul (Fernandes et al. 2000, Loretti et al. 2003). A evidência de broncopneumonia abscedativa (Caso 1), permite a hipótese de tal infecção ter sido o sítio primário desta patologia, tendo em vista que os agentes piogênicos podem alcançar a rete mirabile carotídea por via hematógena ou linfática a partir de processos inflamatórios primários, como sinusites, broncopneumonias, reticuloperitonites, pielonefrites ou mastites (Stöber 2005). A disseminação bacteriana a partir de focos de infecção distantes ocorre através da circulação arterial até a rete mirabile carotídea, enquanto a disseminação a partir dos tecidos moles da cabeça como nos casos de rinite, ocorre através da circulação venosa até o seio cavernoso (Fernandes \& Schild 2007).

O tratamento de bovinos com SAP não é recomendado devido aos elevados custos (Morin 2004) e resultados limitados (Loretti et al. 2003), entretanto em animais de elevado valor zootécnico e em bezerros, devido ao menor porte, o tratamento torna-se economicamente viável para a maioria dos produtores. Recomenda-se a antibioticoterapia de amplo espectro e tratamento de suporte, entretanto mesmo os animais que sobrevivem, podem apresentar sequelas neurológicas (Fernandes et al. 2000, Loretti et al. 2003), como evidenciado no presente caso com incoordenação motora discreta.

É importante realizar o diagnóstico diferencial com as demais doenças que causam sinais clínicos neurológicos semelhantes, dentre elas as enfermidades infecciosas causadas por vírus como a raiva e a meningoencefalite por herpesvírus bovino-5, ou por bactérias como meningite por Escherichia coli, abscessos cerebrais e listeriose; ou ainda com a intoxicação por chumbo e polioencefalomalácia (Barros et al. 2006, Radostits et al. 2007).

No presente trabalho, o diagnóstico definitivo de SAP foi realizado através da associação entre os dados epidemiológicos, achados clínicos, laboratoriais, anátomopatológicos e microbiológicos, confirmando a ocorrência desta síndrome em bovinos na Região Centro-Oeste associada ao uso de tabuleta para desmame interrompido e possível disseminação hematógena a partir de sítios de infecção primários, como a broncopneumonia. A análise do LCR pode ser uma ferramenta útil, associada aos dados epidemiológicos e sinais clínicos, no diagnóstico de doenças do sistema nervoso central em bovinos (Scott 2004, Stockol et al. 2009). Por fim, reitera-se a importância da realização de práticas de manejo adequadas a fim de reduzir a incidência de inúmeras enfermidades, principalmente em animais jovens, dentre elas a SAP.

\section{REFERÊNCIAS}

Barros C.S.L., Driemeier D., Dutra I.S. \& Lemos R.A.A. 2006. Doenças do sistema nervoso de bovinos no Brasil. Coleção Vallée, São Paulo. 207p.

Bath G.F., Van Wyk J.A. \& Pettey K.P. 2005. Control measures for some important and unusual goat diseases in southern Africa. Small Rumin. Res. 60(1-2):127-140.

Dirksen G., Gründer H.-D. \& Stöber M. 1993. Rosenberger, Exame Clínico dos Bovinos. $3^{a}$ ed. Guanabara Koogan, Rio de Janeiro. 419p.

Fernandes C.G., Schild A.L., Riet-Correa F., Baialardi C.E.G. \& Stigger A.L. 2000. Pituitary abscess in young calves associated with the use of a controlled suckling device. J. Vet. Diagn. Invest. 12(1):70-71.

Fernandes C.G. \& Schild A.L. 2007. Abscessos do sistema nervoso, p.202-207. In: Riet-Correa F., Schild A.L., Lemos R.A.A. \& Borges J.R.J. (Eds), Doenças de Ruminantes e Eqüídeos. Vol.1. Gráfica e Editora Palotti, Santa Maria.

Guaraná E.L.S., Souza J.C.A., Afonso J.A.B., Mendonça C.L., Dantas A.F.M., Galiza G.J.N. \& Costa N.A. 2008. Abscesso pituitário em bezerro jovem. Anais II Encontro Nacional de Diagnóstico Veterinário, Campo Grande, MS, p.167-168. (Resumo expandido)

Jain N.C. 1993. Essentials of Veterinary Hematology. Lea and Febinger, Philadelphia. 417p.

Jones M.L \& Allison R.W. 2007. Evaluation of the ruminant complete blood cell count. Vet. Clin. North Am., Food Anim. Pract. 23(3):377-402.

Kramer J.W. 2000. Normal hematology of cattle, sheep and goats, p.1075-1084. In: Feldman B.F., Zinkl J.G. \& Jain N.C. (Eds), Schalm's Veterinary Hematology. $5^{\text {th }}$ ed. Lippincott Williams and Wilkins, Philadelphia.

Loretti A.P., Ilha M.R.S., Riet-Correa G., Driemeier D., Colodel E.M. \& Barros C.S.L. 2003. Síndrome do abscesso pituitário em bezerros associada ao uso de tabuleta nasal para desmame interrompido. Pesq. Vet. Bras. 23(1):39-46.

Mayhew I.G. 1989. Large animal neurology: A handbook for veterinary clinicians. $1^{\text {st }}$ ed. Philadelphia, Lea and Febiger. 380p. 
Morin D.E. 2004. Brainstem and cranial nerve abnormalities: Listeriosis, otitis media and pituitary abscess syndrome. Vet. Clin. North Am., Food Anim. Pract. 20(2):243-273.

Paredes E., Espinoza A., Canal A.M., Zamora J. \& Cubillos V. 1996. Descripcion de un brote de abscesos subhipofisiarios en terneros Hereford. Anais XV Congresso Panamericano de Ciência Veterinária, Campo Grande, MS, p.162. (Resumo)

Radostits O.M., Gay C.C., Hinchcliff K.W. \& Constable P.D. 2007. Veterinary Medicine: A textbook of the diseases of cattle, horses, sheep, pigs and goats. $10^{\text {th }}$ ed. W.B. Saunders, Edinburg. 2156p.

Reilly L., Habecker P., Beech J., Johnston J., Sweeney C. \& Hamir A. 1994. Pituitary abscess and basilar empyema in 4 horses. Equine Vet. J. 26(5):424-426.

Scott P.R. 1995. The collection and analysis of cerebrospinal fluid as an aid to diagnosis in ruminant neurological disease. Brit. Vet. J. 151(6):603-614.
Scott P.R. 2004. Diagnostic techniques and clinicopathologic findings in ruminant neurologic disease. Vet. Clin. North Am., Food Anim. Pract. 20(2):215-230.

Stöber M. 1993. Sistema nervoso central, p.341-362. In: Dirksen G., Gründer H.D. \& Stöber M. (Eds), Rosenberger, Exame Clínico dos Bovinos. $3^{\mathrm{a}}$ ed. Guanabara Koogan, Rio de Janeiro.

Stöber M. 2005. Enfermidades de los órganos del sistema nervioso central, p.933-1057. In: Dirksen G., Gründer H.D. \& Stöber M. (Eds), Medicina Interna y Cirugía del Bovino. Vol.2. $4^{\text {a }}$ ed. Intermédica, Buenos Aires.

Stockol T., Divers T.J., Arrigan J.W. \& McDonough S.P. 2009. Cerebrospinal fluid findings in cattle with central nervous system disorders: A retrospective study of 102 cases (1990-2008). Vet. Clin. Pathol. 38(1):103-112.

Su Y-H., Chen Y. \& Tseng S-H. 2006. Pituitary abscess. J. Clin. Neurosci. 13(10):1038-1041. 